\title{
Prevalence of Syphilis Infection in a Tertiary Rural Hospital: A Five Year Evaluation
}

\author{
${ }^{* 1}$ OLLEY, M, ${ }^{2} \mathrm{OKWU}, \mathrm{MU} ;{ }^{3}$ IGIEBOR, UC; ${ }^{4} \mathrm{ALAO}, \mathrm{BJ}$ \\ ${ }^{*}$ Department of Laboratory Medicine, Igbinedion University Teaching Hospital, Okada, Edo State, Nigeria \\ ${ }^{2}$ Department of Biological Sciences, College of Natural and Applied Sciences, Igbinedion University Okada, Edo State, Nigeria \\ ${ }^{3}$ Department of Laboratory Medicine, Igbinedion University Teaching Hospital, Okada, Edo State, Nigeria \\ ${ }^{4}$ Department of Laboratory Medicine, Igbinedion University Teaching Hospital, Okada, Edo State, Nigeria \\ *Corresponding Author Email: misanoll@yahoo.com; Tel: +2348060319728
}

\begin{abstract}
Syphilis is a blood borne and sexually transmitted disease of global distribution. This study was aimed at determining the trend and prevalence of syphilis across the years among patients attending the Igbinedion University Teaching Hospital, Okada, Nigeria. A retrospective analysis of data of patients attending the Out patients department as well as those attending the anti natal clinic of Igbinedion University Teaching Hospital, Okada, Nigeria from January 2015 to December 2019.Sera samples were screened for Treponema palladium antibody using commercially available immunochromatic rapid Syphilis based test kits. Out of the 741 screened sera in the $2015-$ 2019 study period, $8(1.1 \%)$ were positive for Treponema pallidium antibodies. The prevalence are $0.4 \%, 1.3 \%, 0 \%$, $3.8 \%$ and $2.8 \%$ respectively for the year $2015,2016,2017,2018$ and 2019 respectively. The gender related distribution for the study periods are not statistically significant with $\mathrm{p}$ - values all greater than 0.05 . The prevalence of syphilis is low within this community which is an indication of adherence to preventive measures never the less public awareness remains a medium for eradication of syphilis.
\end{abstract}

\section{DOI: https://dx.doi.org/10.4314/jasem.v24i3.5}

Copyright: Copyright $\left({ }_{0} 2020\right.$ Olley et al. This is an open access article distributed under the Creative Commons Attribution License (CCL), which permits unrestricted use, distribution, and reproduction in any medium, provided the original work is properly cited.

Dates: Received: 16 November 2019; Revised: 11 January 2020; Accepted: 22 February 2020

Keywords Rapid Syphilis test kit, Immunochramatogenic, Treponema pallidium

Treponema pallidium is an infectious agent responsible for the sexually transmitted disease syphilis (Mark Gladwin and Bill Trattler, 2009) and also a known global public health problem (WHO, 2008). Infection is usually by penetration of the organism through intact mucous membrane or by invading through epithelial abrasion which if untreated leads to four different clinical stages which are Primary syphilis, Latent syphilis, Tertiary and Congenital syphilis (Weiss and Adkinson, 2005). Pennicillin still remains the recommended therapy for syphilis (Tramont, 1995), resistance to penicillin has not yet been found among clinical isolates (Tramont, 2005) but there is a potential for the acquisition of extra chromosomally mediated antibiotic resistance (Norgard and Miller, 1981). The first and third generation cephalosporin antibiotics in particular ceftriaxone are also effective in treating syphilis at the early onset of disease and late latent syphilis (CDC, 2010) because of its ability to cross the blood brain barrier (Korting et al., 1993). World Health Organization, 2012 estimates that 10.6 million new cases of syphilis in 2008, with 15-40 years being vulnerable with no vaccines currently available. In Nigeria however, prevalence of syphilis was reported to be about $0.8 \%$ in 2005 (FMH, 2007). Until now, there is no representative survey on syphilis within this region on the prevalence of syphilis among patients attending the General and outpatient department of the Igbinedion University Teaching Hospital Okada for the past 5years. The aim of the study is to determine the prevalence of syphilis among patients visiting the General out patients department of the Igbinedion University Teaching Hospital, Okada in the past five years.

\section{MATERIALS AND METHODS}

Study Area: The study was carried out in a private tertiary hospital located in Okada town, Ovia North east local government area of Edo state. The occupation of inhabitants is predominantly farming.

Study design: A retrospective analysis of data involving patients attending the out patients department as well as those attending the anti natal clinic of the Igbinedion university Teaching Hospital for January 2015 to December 2019, no control groups are included; patients are those presenting with urinary tract infections. Followed up patients were excluded from the study. 
Specimen Collection: Blood samples collected into EDTA anticoagulant bottles were used for the analysis.

Serological tests: Separated plasma dispensed into sterile plain bottles was used for the analysis using the Syphilis Rapid Test Strip (RTS) produced by Acumen Diagnostic, Germany. All reactive syphilis samples (containing $T$. palladium antibodies both $\mathrm{IgG}$ and IgM) were further tested and confirmed with TPHA (Teco Diagnostics - USA). Tests were done according to the manufacturer's instruction.

Data Analysis: The proportions were calculated for prevalence. The prevalence for each year was calculated by evaluating its percentage. The data generated from this study were presented using descriptive statistics.

\section{RESULTS AND DISCUSSIONS}

A total of 741 patients were enlisted for the study within the time period of 2015 to 2019 . The prevalence varies from $0.4 \%$ to $2.8 \%$ as shown in Table 1 . Likewise the percentage distribution of syphilis infection among patients in relation to Gender is not statistically significant with $\mathrm{p}$ value greater than 0.05 in all years of incidence. Figure 1 shows the cross section distribution of syphilis infection among attendee, the year 2017 did not record any positive case, while 2015 and 2016 had only female patients been positive for syphilis infection.

Table 1: Prevalence of syphilis infection

\begin{tabular}{llll}
\hline Year & Positive (RTS) & n & Prevalence (\%) \\
\hline 2015 & 1 & 265 & 0.4 \\
2016 & 2 & 156 & 1.3 \\
2017 & 0 & 168 & 0 \\
2018 & 3 & 80 & 3.8 \\
2019 & 2 & 72 & 2.8 \\
TOTAL & & & 741 \\
\hline
\end{tabular}

Table 2: Distribution of Syphilis infection with respect to Gender

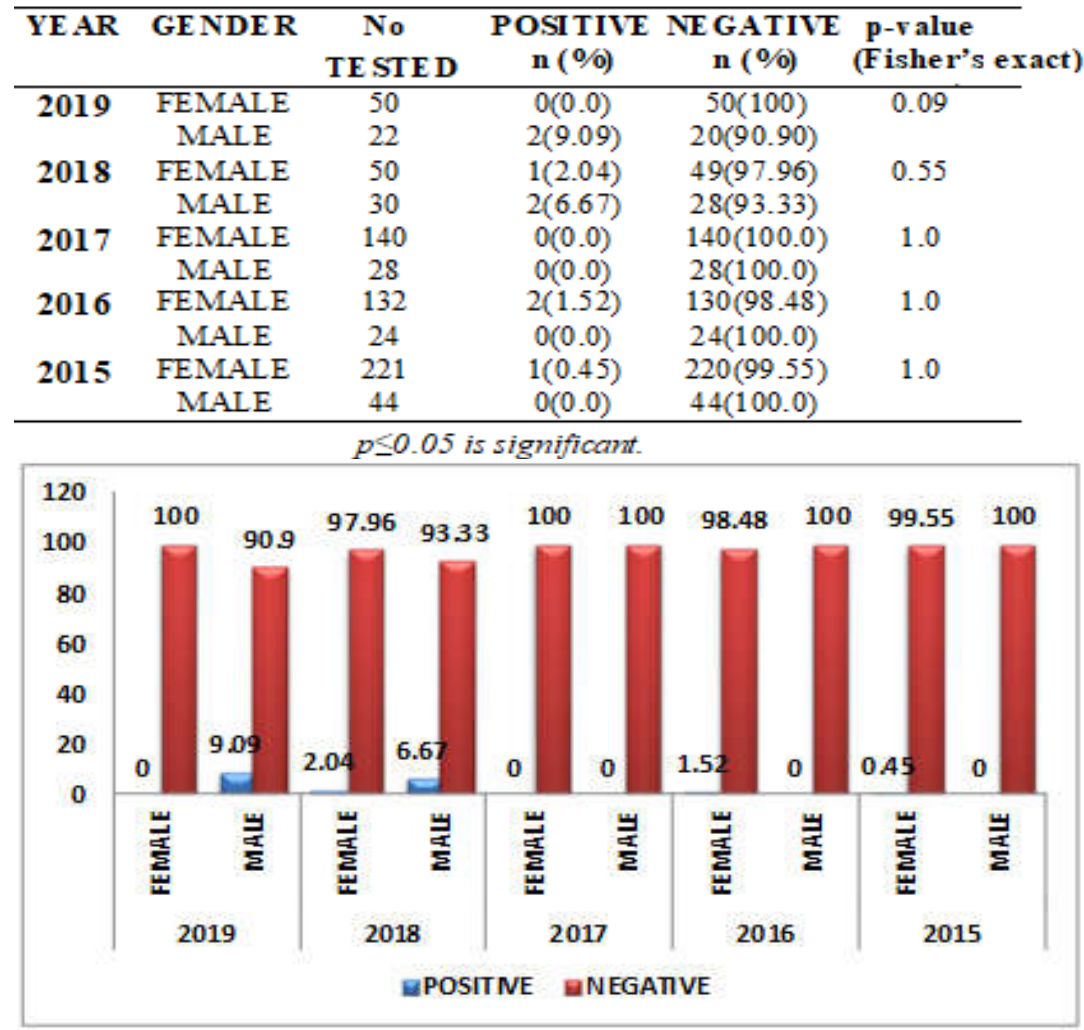

Fig 1: Distribution of Syphilis infection in five years duration

The results of this study have demonstrated the danger pose by this emerging disease of public Health importance, which is syphilis, within this rural community. In this study, the prevalence obtained varies within the five years that is $0.4 \%, 1.3 \%, 0 \%$, $3.8 \%$ and $2.8 \%$ respectively for $2015,2016,2017$, 
2018 and 2019 respectively. This is lower when compared to the prevalence reported in Federal Medical Centre, Abakaliki, Ebonyi State, Nigeria with $30 \%$ (Federal Ministry of Health, 2001) and similar to the prevalence obtained in Maiduguri (Chikwem et al., 1997) and Ile Ife (salawu et al., 2010) with 3.6\% and $2.6 \%$ respectively and much lower value of $0.1 \%$ has been reported in Port Harcourt (Ejele and Ojule, 2004). However, as reported in some African countries, prevalence of syphilis are as low as $2.0 \%$ in Cotonou, $4.0 \%$ in Kisumu, 6\% in Yaounde (Sule et al., 2010),3.9\% in Burkina Faso (Nagalo et al.,2011), Ethiopia, 0.1\% (Yusuf et al., 2016), Kenya, 1.2\% (Kamande et al., 2016), 4.9\% in Ghana (Andrew et al., 2003).This low prevalence obtained in this study could be as a result of the social economic life style of individuals in this rural community and likewise the disparity in the prevalence elsewhere may be attributed to geographical differences associated with cultural and religious belief. The gender related distribution of syphilis had a higher rate of infection among male sex with a prevalence of $3.2 \%$ as compared to $0.8 \%$ for female gender for the five years study. This rate of infection is in disagreement with the findings of Todd et al., 2001 who reported a higher prevalence of $9.1 \%$ of $T$. palladium in female to $7.5 \%$ in males for an African population setting, but on different strata, 2016 and 2015 had a higher prevalence for female gender. This low prevalence could be attributed to proper use of preventive measures such as condom, screening of blood prior to transfusion and awareness of sexually transmitted infections. However, the rate of infection among gender is not statistically significant for the study periods.

Conclusion: Data collected from this survey provides useful information in the distribution of syphilis infection within this community, this data obtained could be considered as baseline of its prevalence in future studies. Despite this low prevalence of syphilis, emphasis should be placed on its awareness as a sexually transmittable as well as transfusion transmittable disease so as to completely eradicate this infection

Acknowledgement: The authors acknowledge staffs of Igbinedion University Teaching hospital for their contribution to managing data collection.

\section{REFERENCES}

Andrew, AA; William, K; Henry, A (2003). Prevalence of antibodies to syphilis among blood donors in Accra, Ghana. Jpn. J. Infect. Dis.56:165-167.
Centers for Disease Control and Prevention (2010). Sexually Transmitted Treatment Guidelines. MMWR 49: 1- 102

Chikwem, JO; Mohammed, I; Okara, GC (1997). Prevalence of transmissible blood infections among blood donors at the University of Maiduguri Teaching Hospital, Maiduguri, Nigeria. East Afr. Med. J. 74:213-216.

Ejele, OA; Ojule, AC (2004). The prevalence of hepatitis-B surface antigen (HBsAg), among prospective donors and patients in Portharcourt, Nigeria. Niger. J. Med. 13:336-338.

Federal Ministry of Health (2007). National HIV/STI Control Programme, Nigeria.

Kamande, MW; Kibebe, H; Mokua, J (2016). Prevalence of transfusion transmissible infections among blood donated at Nyeri satellite transfusion Centre in Kenya. IOSR J. Pharm. 6:20-30.

Korting, HC; Walther, D;Riethmullere, U; Meurer, M (1993). Efficacy of ceftriaxone in the treatment of incubating syphilis in rabbits. Chemother. 39: $331-335$

Mark Gladwin, MD and Bill Trattler, MD (2009). Clinical Microbiology made ridiculously simple. Edition 4 MedMaster, Inc, Miami

Nagalo, MB; Sanou, M; Bisseye, C; Kaboré, MI; Nebie, YK; Kienou, K (2011). Seroprevalence of human immunodeficiency virus, hepatitis $\mathrm{B}$ and $\mathrm{C}$ virus and syphilis among blood donors in Koudougou (Burkina Faso) in 2009. Blood Transfus. 9:419-24.

Norgard, MV and Miller, JN (1981). Plasmid DNA in Treponema palladum (Nichols): potential for antibiotic resistance by syphilis bacteria. Sci. 213: 553- 555.

Nwankwo, E; Momodu, I; Umar, I; Musa, B; Adeleke, S (2012). Seroprevalence of major blood-borne infections among blood donors in Kano, Nigeria. Turk J Med.42:337-341.

Salawu, L; Bolarinwa, RA; Adegunloye, AB (2010). HBsAg, anti-HCV and VDRL in blood donors: prevalence and trends in the last three and a half years in a tertiary healthcare facility in Ile-Ife, Nigeria. Int. J. Med. Sci.2:335-341. 
Todd, J; Mungati, K; Groskurth, H (2001). Risk factors for active syphilis and TPHA seroconversion in a rural African population. Sexually trans. Infect. 77(1):37-45

Tramont, EC (2005). Treponema pallidium (syphilis). In: Mandell, GL; Benneth, JE and Dolin, R. Principles and Practice of Infectious Diseases $6^{\text {th }}$ ed. New York. Churchill Livingston: 2768- 2785

Weiss, ME; Adkinson, NF (2005). Beta lactam allergy. In: Mandell, GL; Benneth, JE and Dolin, R. Principles and Practice of Infectious Diseases $6^{\text {th }}$ ed. New York. Churchill Livingston: 318 325 .
World Health Organization (2012). Global incidence and prevalence of selected curable sexually transmitted infections- 2008

Yusuf, M; Almayehu, B (2016). Seroprevalence of transfusion trnsmitted infection among blood donors of Jijiga blood bank, East Ethiopia; retrospective 4 years study. BMC Res. Notes. 9:129. 